\title{
There Is No 'Virtual Learning': The Materiality of Digital Education
}

\author{
Lesley Gourlay $(\mathbb{0}$
}

Department of Culture, Communication and Media, Institute of Education, University College London, United Kingdom

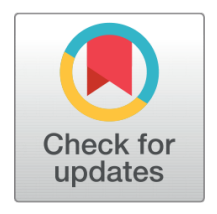

Received 2020-09-16
Revised 2020-10-01
Accepted 2020-10-26
Published 2021-01-15

Corresponding Author

Lesley Gourlay,

I.gourlay@ucl.ac.uk

Department of Culture,

Communication and Media, UCL Institute of Education, University College London, 20 Bedford Way London WC1H OAL

DOI https://doi.org/10.7821/

naer.2021.1.649

Pages: 57-66

Funding: The research project UCL Moving to Online Teaching and Homeworking is supported by UCL Institute of Education, and is led by Allison Littlejohn.

Distributed under

Creative Commons CC BY 4.0

Copyright: ( ) The Author(s)

\section{ABSTRACT}

The distinction between face-to-face and distant digitally-mediated educational engagement is a complex one, and the two modes are often combined in practice, via 'blended learning' or the use of a VLE to support campus-based teaching. The current Covid-19 pandemic has thrown this distinction into relief, in a context where educationalists have been forced to move to fully distant engagement in a very short timeframe. This paper explores how this predicament has brought to the fore the nature of our engagement with digital knowledge practices and screen-based communication, arguing that the notion of 'virtual learning' is a flawed one. Instead, adopting a sociomaterial perspective, it argues that all aspects of digital engagement are in fact grounded in material and embodied entanglements with devices and other artefacts.

\section{Keywords COVID-19, SOCIOMATERIAL, DIGITAL ENGAGEMENT,} EMBODIMENT, ONLINE LEARNING

\section{INTRODUCTION}

The distinction between face-to-face and distant digitally-mediated educational engagement is a complex one, and the two modes are often combined in practice, via 'blended learning' or the use of a Virtual Learning Environment to support campus-based teaching. The current Covid-19 pandemic has thrown this distinction into relief, in a context where educationalists have been forced to move to fully distant engagement in a very short timeframe. The implications of this change have been wide-reaching and profound, with academic staff and students being forced to adapt rapidly to this sudden change in their mode of teaching, learning, doing research and communicating. This has had a range of effects, which are becoming apparent in the emerging body of research focused on the impact of the virus on education.

The dominant discourse surrounding this shift centres on the nature of the digital, and arguably focuses particularly on the digital as a disembodied realm, outside of the material world. Some of the terminology commonly used to describe this, I will argue, adds to this notion, such as 'virtual learning' or 'online learning'. The adjective 'virtual' is defined by

\section{OPEN ACCESS}


the Cambridge online dictionary in two ways; firstly it can mean "almost a particular thing or quality", and secondly it can be "used to describe that which can be done or seen using computers or the internet instead of going to a place, meeting people in person etc." (Cambridge Online Dictionary, 2020). This definition is noteworthy, in that it makes a contrast between doing something using computers, instead of 'going to a place', or meeting people 'in person'. The expression 'in person' is also worthy of attention, defined by Cambridge as follows "If you do something or go somewhere in person, you do it or go there yourself" (Cambridge Online Dictionary, 2020). We also use the expression 'meet in person' to refer to physical and temporal co-presence, the idea of being 'with' other people also relies on this. The contrast, implicitly, is that digital engagement does not involve going to a particular place, and not doing something in person'. This, I suggest, is indicative of two wider notions which dominate the way we think about educational technology. The first is that the digital exists outside of physical, material movement, placement or practices. The second is that it does not involve the body, the 'person', in the sense of doing something 'in person'.

The assumed hard binary between the digital and the analogue arguably pervades mainstream educational policy and practice. On the basis of this assumption, one could expect that the current Covid-19 crisis and resultant move to home working and digitally-mediated teaching and learning has led to a situation in which the importance of physical location and bodily practices are no longer salient. There is no need to dress in a particular 'professional' manner, travel to the campus at the assigned time, find a particular room, set up the computer equipment, wait for the students to arrive and settle down, then address them verbally while physically facing them, observing the social, material and linguistic conventions that constitute 'teaching'. All these requirements are removed or fundamentally changed in the homeworking scenario. The notion of the 'virtual', in contrast, is replete with ideas of nonmateriality and disembodiment. In this paper I will present a challenge to the concept of 'virtual learning', arguing that digital engagement is always -and entirely- a set of material and embodied practices. Drawing on sociomaterial and posthuman perspectives, I will focus on the materiality of the digital, the embodied nature of engagement with devices, physical objects and space, and the performativity of talking to the screen. I conclude by arguing that, in a sense, there is no such thing as 'virtual learning', as all of the engagement and processes it consists of take place via sociomaterial and embodied practices.

\section{THE MATERIALITY OF THE DIGITAL}

The notion that digital technologies enable a complete break from the restrictions of materiality is a pervasive trope in educational technology, alongside the idea that digital engagement leads to individuals being 'freed' in some sense from physical or bodily constraints. Clearly, digital technology allows us to connect instantaneously with others across large distances, where in the past, physical systems such as mail delivery would have been required. Digital devices and the use of wireless broadband, in contrast, may give us the impression that our communications and digital resources are non-physical, almost appearing as a form of disembodied 'magic', which is assumed to be inherently liberatory, a stance which has 
already been critiqued in the literature (Bayne, 2004; Land, 2005; Selwyn, 2016).

However, this image remains dominant, and under its influence the material nature of the digital is arguably elided. Digital systems consist of hardware, which is clearly physical. However, what is less obvious is the materiality of other elements of digital systems. Kirchenbaum, in his discussion of electronic textuality, describes it as 'locatable':

...even though we are not used to thinking of it in physical terms. Bits can be measured in microns when recorded on a magnetic hard disk... When a CD-ROM is burned, a laser superheats a layer of dye to create pits and lands, tiny depressions on the grooved surface of the platter. The length of these depressions is measured in microns, their width and depth in nanometers.

(Kirchenbaum, 2012)

Kirchenbaum draws on Thibodeau's (2002) three-part model of digital objects. There are physical objects such as the CD-ROM referred to above; logical objects such as data as it is recognized by particular software; and conceptual objects, which Thibodeau sees as "...objects we deal with in the real world" (Thibodeau, 2012, in Kirchenbaum, 2012, p. 3) such as a digital photo. For Thibodeau, a digital object is something whose ontology includes all three of these aspects. Kirchenbaum also refers to posthuman theorist Katherine Hayles's concept of technotexts:

The physical attributes constituting any artefact are potentially infinite; in a digital computer, for example, they include the polymers used to fabricate the case, the rare earth elements used to make the phosphors in the CRT screen, the palladium used for the power cord prongs, and so forth. From this infinite array, a technotext will select a few to foreground and work into its thematic concerns. Materiality thus emerges from interactions between physical properties and a work's artistic strategies. For this reason, materiality cannot be specified in advance, as it if pre-existed the specificity of the work. An emergent property, materiality depends on how the work mobilizes its resources as a physical artefact as well as the user's interaction with the work and the interpretive strategies developed strategies that include physical manipulations as well as conceptual frameworks. In the broadest sense, materiality emerges from the dynamic interplay between the richness of a physically robust world and human intelligence as it crafts this physicality to create meaning.

(Hayles, 2002, p. 32-33)

These analyses present us with a challenge to the notion that digital practices more broadly are, by their nature, nonmaterial and ephemeral. However, in order to work towards a more coherent conception of digital engagement from a sociomaterial standpoint, the day-to-day micro practices of digital work should also be re-examined. 


\section{EMBODIED ENTANGLEMENTS}

In addition to the thinking of the digital as a form of disembodied 'magic' at the level of devices and systems, there is also a tendency to extrapolate from this, a conception of digital engagement more broadly as disembodied practice. The digital is frequently discussed in terms which suggest a 'breaking free' from the constraints of physical spaces and temporal frames, particularly when discussing mobile digital devices. This is often combined with what might be criticised as a somewhat neoliberal and thoroughly humanist fantasy of the human subject, whose capacities are imagined to be extended or even transcended via digital technologies. The implication is that material artefacts and the human body are not relevant, and that engagement is friction-free.

However, a brief reflection on the reality of digital engagement soon renders this image questionable. Mobile phones must be handled, and can be dropped, and screens broken, batteries go flat, power leads tangle, and laptops overheat. The physicality of devices is -I propose- always salient. Engagement is necessarily situated in a particular location, there is no 'escape' from the material surround, whether the device is being used at home, in an airport, or walking down the street. Additionally, these physical spaces should not be viewed as undifferentiated neutral backdrops -they must always be managed, negotiated with. A chair or space must be found at the airport, with available WiFi in that area. An awareness of surroundings and of other people is vital when using devices in public. At home, a suitable arrangement of space and furniture must be created and actively maintained in order to engage when using a desktop or laptop. An electrical supply and WiFi is needed. These devices are always in contact with the physical substrate of furniture, or held and touched by the human hand. These points may seem obvious, but detailed analysis of sociomaterial and embodied entanglement with the digital is, I would argue, often neglected at the expense of focus on the practices unfolding on the screen, 'online'.

However, there has been a growing recognition of the perspectives of sociomateriality, Science and Technology Studies, posthumanism, spatiality and awareness of embodiment on education in recent years (Acton, 2017; Fenwick, Edwards, \& Sawchuk, 2011; Gourlay, 2020a; Gourlay \& Oliver, 2018; Hamilton \& Friesen, 2013; Leander \& Boldt, 2012). Adams and Thompson (2016), in a book-length piece, demonstrate how posthuman perspectives which recognise the complex nature of human and nonhuman agency, can be brought to bear on the close examination of digital practices. They use a phenomenological approach, through a series of heuristics, to examine in detail the nature of interaction and engagement with digital objects.

\section{DISTANCE, ABSENCE AND PRESENCE}

If we accept the importance of the material in digital engagement, then broaden it out, how do we 'locate' the university in sociomaterial terms? Bayne, Gallagher, and Lamb (2014), drawing on the 'new mobilities' paradigm in social science (Sheller \& Urry, 2006; Urry, 2007) examine how 'distance' students conceptualise the campus, situating the work within an emergent strand of educational research influenced by geography and theorisation of 
space (Edwards, Tracy, \& Jordan, 2011; Enriquez, 2011, 2013; Taylor, 2009). They argue that, in the light of distance education, the university cannot be seen as a static 'container', but instead should be regarded as an 'enactment' (Edwards et al., 2011, p. 22), by which '...hosts, guests, buildings, objects, and machines are contingently brought together to produce certain performances in certain places at certain times' (Sheller \& Urry, 2006, p. 14, in Bayne et al. 2014, p. 571).

They report on a study involving interviews and visual data, collected from mature parttime postgraduate students studying entirely online in a range of countries. Participants were interviewed using online synchronous chat on Skype, and were also later asked to create a 'digital postcard' representing their study environments, these consisted of a visual image plus a sound recording. The interviews focused on how the university space was enacted by these students. Their analysis is based on the theorisation of spaces developed in Mol and Law (1994) and Law and Mol (2001), building on the categories of network space, which is defined by stable relations between elements, fluid space, which is characterised by shifting and volatile boundaries and network relations, and fire space, "... a space defined by the complex intersections of presence and absence” (Bayne et al., 2014, p. 572). Their analysis reveals what they call 'topological multiplicity' across the accounts provided by the participants, in which the university is seen to be 'enacted' at a distance via various conceptions of spatiality, as opposed to falling on one side or other of a simplistic 'static' versus 'mobile' binary. They identified several categories in the student responses; the first is 'homing and the sentimental campus', in which students expressed an emotional or family connection with the city of Edinburgh where the university campus is located. The second is 'the metaphysics of presence, or 'campus envy', which they locate in terms of fire space:

Within a topology of fire, the presence of a 'thing', an object - its constancy depends on 'simultaneous absence or alterity' it 'evokes a specific version of the relationship between presence and absence: a link between a single present centre and multiple absent Others. In the context of this study, we might see the distance programme as depending for its form, on its 'constancy', on the flickering patterns enacted between the 'presence' of the university and its multiple, 'absent' students (or indeed, conversely, between its multiple present students and their absent campus).

(Bayne et al. 2014, p. 577)

The third category is 'the imagined campus', in which highly mobile students work in a fluid space of 'churn and flow' (Mol \& Law 1994, in Bayne et al. 2014, p. 580) which is in continual flux. They argue that in this case, notions of presence and absence are less salient, and the physical campus is not regarded as somehow more 'authentic'; 'The university here is simultaneously real and imagined, absent and present, having a 'constancy' which is playfully and knowingly ambiguous, but nonetheless deeply significant.' (Bayne et al. 2014, p. 581). They argue that the physical campus is a significant 'mooring' for these students, even though they never visit it in person, and conclude that more nuanced understandings of academic geographies in higher education are needed in the context of contemporary arrangements 
such as branch campuses and MOOCs.

\section{ACADEMIC GEOGRAPHIES UNDER COVID-19}

This important paper opens up new understandings of how we might conceptualise orientations towards space, distance, absence, and presence in digital higher education. In the current context of the Covid-19 crisis, which has forced thousands of students and academics to abandon their campuses and work remotely, this call becomes ever more urgent. In March 2020, in the UK and also around the world, university campuses were suddenly closed in response to the Covid-19 pandemic and the need to 'lock down' the population to contain the spread of the virus. This took place with scant warning or preparation, students were required to return home at short notice, and academics and professional services staff were asked to work from home.

In the recent Moving to Online Teaching and Homeworking interview study with academics under lockdown, Gourlay (2020b) found a range of orientations to the conditions of enforced confinement among the participants. The analysis revealed a situation which in some ways corresponded to traditional notions of being under 'quarantine' in order to shelter from a dangerous disease and protect others. However, in an important respect, it was very different. A striking feature of their accounts was the extent to which their activities centred on communicating with others, predominantly on digitally-mediated video calls. In this regard, although each individual was separated from the others in the academic community of scholars, they were simultaneously in frequent communication. This contrasts with a situation in which a community of people, such as sailors from a ship at the time of the plague in early modern Europe, would be confined together. In sociomaterial and spatial terms, this is an important characteristic of the lockdown; the members of the university were dispersed across the local area and also the world, as many had returned to their home country. Extending the comparison with the plague ship, the university had also been emptied out of its occupants, and stood abandoned, closed and out of bounds.

In sociomaterial terms, the study found that, as opposed to 'freeing' the participants form the confines of the material and embodied via a move to the liberating world of digital technology, the salience of physical artefacts, spaces and the body were in fact brought into sharp relief. The locked-down academics reported on a range of complex challenges they faced, attempting to create and maintain arrangements of space, furniture and devices in such a way as to be able to enact this communication, particularly on-screen, which required a particular type of 'professional' verbal and embodied performance, in which the academic identity should be enacted. The fine-grained, contingent manipulation of desks, screens and artefacts was achieved in domestic space, in most cases in areas of the house which were not already designated as home offices. Instead, participants variously reported repurposing a bedside table, creating a 'tower' construction of boxes and tables to bring a screen to the right height, containing domestic chaos around the screen where childcare was simultaneous with work, and rigging up a curtain to form a 'professional' backdrop for online talks. What is striking about these accounts is the extent to which these digital practices were 
messy assemblages of human and nonhuman actors, unfolding in the nitty-gritty material and spatial circumstances of the homes in which the academics were locked down. The study did not include data from students, but it would be reasonable to assume that students under lockdown would be engaged in similar practices and entanglements, in order to take part in digitally-mediated classes and other forms of engagement.

Clearly, the Covid-19 crisis presented a very particular set of challenges to academics and students, particularly at the start of the lockdown period, when specialist adaptive equipment which might have made arrangements easier had not yet been acquired. However, I would argue that this extreme example illustrates and brings into relief a broader and more fundamental point about digital engagement as discussed above - that is essentially a material and embodied practice. In this regard, it could be argued that the purportedly rarefied and disembodied world of 'online learning', in a certain respect, does not take place 'online' at all, but is always and entirely sociomaterially-situated.

Returning to Bayne et al. (2014) analysis, it is interesting to consider what relationship these academics and their students have with the physical campus. Their analysis reveals a range of orientations which refer to the 'normal' state of affairs pre-virus, in which the campus is open and is regarded by some as the default 'location' of the university. Under lockdown, there is no functioning physical campus to refer to, except for essential services such as the computer servers. The 'sentimental campus', 'campus envy' and 'the imagined campus', cannot apply in this situation. Instead, the campus is characterised by its absence, an uncanny emptiness. This raises the question about where exactly the university is located under lockdown - in a certain respect, it could be argued that it resides primarily in the tens of thousands of dispersed bodies of its community, and only persists by virtue of the private, fragile, and contingent sociomaterial entanglements they have made with digital devices in their homes. The university then appears to have 'gone online', but a sociomaterial reading would suggest an alternative form of understanding of this predicament, one which grounds it firmly in the realm of the material and embodied.

\section{CONCLUSIONS}

This paper has sought to question the assumption that the digital confers an 'escape route' to the messy contingencies of material assemblages and embodied knowledge practices. Questioning -alongside previous commentators- mainstream assumptions and discourses surrounding the digital which suggest it offers a disembodied and frictionless alternative characterised by 'free-floating' digitally-mediated agency, instead it has drawn attention to the intrinsic materiality of digital systems, and the human / nonhuman nature of practices and entanglements around the digital in the day-to-day. It has also explored the complexities of spatial arrangements and individuals' orientations in the context of distance higher education, linking this analysis with the recent Covid-19 lockdown of university communities. I have proposed that this unprecedented situation has provided a stark illustration of the fundamentally material and embodied nature of digital knowledge practices, suggesting that this calls into radical doubt the validity of the term 'virtual learning', and those 
terms associated with it. It is always 'in person', even when the person is alone and home in front of a screen. It is clear that digital technology forms part of the set of entanglements and practices under discussion here. However, I would argue in conclusion the texts and images which appear on screens are essentially both material, and also the results / effects of embodied practices, rather than replacing them.

Viewed in this way, the implications for practice and policy might be considered. If devices, workstations and rooms are regarded as containers for teaching, learning or research, then the work itself, the engagement, is implicit located elsewhere. But where is it 'enacted' in that case? My contention is that is nowhere else, but is located / situated / enacted only there, in entanglements with the teetering tower of boxes, the unstable arrangement on the bedside table, or in front of the temporary curtain on the bedroom wall. If these devices and artefacts are seen as essential and inseparable agents of practice, as opposed to tools, equipment or 'workstations', then the implications for practices are worthy of consideration.

Although it may seem a subtle distinction, I would suggest that shifting the focus of practice towards the material and embodied allows us to view digital engagement as fully entwined with it, rather than seeing the material and embodied as context, or means to practice. This allows us to conceptualise digital knowledge practices in a more holistic manner. Issues of access to suitable devices and spaces then become part of practice, and can be brought to the fore. In pedagogic terms, greater prominence can be placed on the embodied nature of practice, thinking about length of time on screen, people's physical needs for movement, physical comfort and breaks. The priorities of students with disabilities could be made more explicit. The (often gendered) reality of domestic contexts could potentially be made less hidden, and more integrated. These changes could move the conception of digital engagement away from the fantasy of the idealised free-floating human subject, and towards a more diverse, looser conception of engagement which takes in what is going on around the screen, as opposed to treating the screen as a narrow portal for a particular type of performance.

To achieve this, a greater degree of focus on the materiality of engagement would be required within teaching and learning processes. This might involve finding out more about students' circumstances at the start of a course, via pre-course surveys for example, or a more qualitative or ethnographic approach might be taken. Academic teaching staff might model this form of openness but showing students their own settings and assemblages. However, this type of disclosure conflicts with the understandable desire to maintain boundaries and privacy in the domestic space, where sharing of details of surroundings may feel uncomfortable, expose inequalities, or even place participants at risk. This is a tension inherent in digital engagement from home -the need to acknowledge the complex realities of achieving engagement, alongside the heightened sense of 'living at work' which may result from this erosion of the public and private, the professional and the domestic sphere. This raises interesting questions about performance of professional selves, and how these performances might serve to simultaneously constrain or elide subjectivities and messy contingencies, but may also confer a sense of neutrality and anonymity which could itself feel 
safer and more conducive to self-expression. In terms of future directions for research and enquiry, I regard these questions and tensions as worthy of more in-depth consideration.

\section{REFERENCES}

Acton, R. (2017). Place-people-practice-process: Using sociomateriality in university physical spaces research. Educational Philosophy and Theory, 49(14), 1441-1451. https://doi.org/ 10.1080/00131857.2017.1309637

Adams, C., \& Thompson, T. (2016). Researching a Posthuman World: Interviews with Digital Objects. Palgrave Macmillan. https://doi.org/10.1057/978-1-137-57162-5

Bayne, S. (2004). Smoothness and striation in digital learning spaces. E-learning, 1(2), 302-316. https://doi.org/10.2304/elea.2004.1.2.6

Bayne, S., Gallagher, M. S., \& Lamb, J. (2014). Being 'at' university: the social topologies of distance students. Higher Education, 67(5), 569-583. https://doi.org/10.1007/s10734-013-9662-4

Edwards, R., Tracy, F., \& Jordan, K. (2011). Mobilities, moorings and boundary marking in developing semantic technologies in educational practices. Research in Learning Technology, 19(3), 219-232.

Enriquez, J. (2011). Tug-o-where: situating mobilities learning (t)here. Learning. Media and Technology, 36(1), 39-53.

Enriquez, J. (2013). Being(t)here: mobilising 'mediaspaces' of learning. Learning, Media and Technology, 38(3), 319-336. https://doi.org/10.1080/17439884.2012.685744

Fenwick, T., Edwards, R., \& Sawchuk, P. (2011). Emerging Approaches to Educational Research: Tracing the Sociomaterial. Routledge.

Gourlay, L. (2020a). Posthumanism and the Digital University: Texts, Bodies and Materialities. Bloomsbury. https://doi.org/10.5040/9781350038202

Gourlay, L. (2020b). Quarantined, sequestered, closed: theorising academic bodies under Covid-19 lockdown. Postdigital Science and Education, 2, 791-811. https://doi.org/10.1007/s42438-020 -00193-6

Gourlay, L., \& Oliver, M. (2018). Student engagement in the digital university: Sociomaterial assemblages.. Retrieved from https://doi.org/10.4324/9781315647524

Hamilton, E., \& Friesen, N. (2013). Online Education: A Science and Technology Studies Perspective / Éducation en ligne: Perspective des études en science et technologie. Canadian Journal of Learning and Technology / La revue canadienne de l'apprentissage et de la technologie, 39(2). https://doi.org/10.21432/T2001C

Hayles, K. (2002). Writing Machines. MIT University Press. https://oi.org/10.7551/mitpress/ 7328.001 .0001

Kirchenbaum, M. (2012). Mechanisms: New Media and the Forensic Imagination. MIT University Press.

Land, R. (2005). Embodiment and risk in cyberspace education. In R. Land \& S. Bayne (Eds.), Education in Cyberspace (pp. 149-164). Routledge.

Law, J., \& Mol, A. (2001). Situating Technoscience: An Inquiry into Spatialities. Environment and Planning D: Society and Space, 19(5), 609-621. Retrieved from https://doi.org/10.1068/d243t $10.1068 / \mathrm{d} 243 \mathrm{t}$

Leander, K., \& Boldt, G. (2012). Rereading 'a pedagogy of multiliteracies': bodies, texts and emergence. Journal of Literacy Research, 45(1), 22-46. https://doi.org/10.1177/1086296X12468587

Mol, A., \& Law, J. (1994). Regions, Networks and Fluids: Anaemia and Social Topology. Social 
Studies of Science, 24(4), 641-671. https://doi.org/10.1177/030631279402400402

Press, C. U., \& Cambridge Online Dictionary. (2020). Retrieved from https://dictionary.cambridge .org

Selwyn, N. (2016). Is Technology Good for Education? Polity.

Sheller, M., \& Urry, J. (2006). The New Mobilities Paradigm. Environment and Planning A: Economy and Space, 38(2), 207-226. https://doi.org/10.1068/a37268

Taylor, C. (2009). Towards a geography of education. Oxford Review of Education, 5(5), 651-669. https://doi.org/10.1080/03054980903216358

Thibodeau, K. (2002). Overview of technical approaches to digital preservation and challenges in the coming years. The State of Digital Preservation: An International Perspective. Retrieved from https://www.clir.org/pubs/reports/pub107/thibodeau/

Urry, J. (2007). Mobilities. Polity Press. 